\title{
Major limb amputations in El Obeid Hospital, Western Sudan
} El Bushra Ahmed Doumi ${ }^{1}$, Aisha Jabir Ali ${ }^{2}$.

\begin{abstract}
:
Objectives: To study the causes and pattern of major limb amputations in El Obeid Hospital, Western Sudan.

Patients and methods: The records of 50 major limb amputations performed in patients admitted to the University Surgical Unit at El Obeid Teaching Hospital, Western Sudan in two years were retrospectively studied.
\end{abstract}

Results: $72 \%$ of the victims were males. The mean age was 51 years \pm SD $34.5 .36 \%$ of the amputations were emergency procedures. Sepsis, trauma and vascular causes accounted for $40 \%, 32 \%$ and $16 \%$ respectively. The upper limb amputations were due to crushed missile injuries, lacerated wounds of animal bites and gangrenous limbs after post-fracture tight splintage by traditional bone setters.

Conclusions: The study showed that $96 \%$ of the causes were potentially preventable, and that establishment of a Prothetic-Orthotic Centre is needed in this part of the country.

Key words: Limb amputations.

\section{Introduction}

Amputation is one of the oldest surgical procedures dating back to prehistoric times. It was described in the Babylonian code of Hammurabi inscribed on black stone, some $1700 \mathrm{BC}^{1}$. It is estimated that 1.2 million individuals are living with an amputation; and that 185,000 are performed each year worldwide ${ }^{2}$. Major limb amputation is defined as any amputation at or proximal to wrist or ankle ${ }^{3}$. Limb loss has a devastating impact on patients. Its impact can be a frightening and challenging experience for the amputees and their families. Amputees become the responsibility of the health service ${ }^{4}$ and if not well looked after, they may continue crippled for life. This is the first documentation of this problem from the central west of Sudan.

\section{Patients and methods}

Fifty patients had major limb amputations in the wards of the University Surgical Unit, El Obeid Teaching Hospital, Western Sudan; from March 2004 to February 2006. The records of those patients were retrospectively studied to the pattern, causes and outcomes of those procedures. The data were analyzed using the SPSS computer package.

\section{Results}

There were 50 patients, 36 of them were males $(72 \%)$ with a male: female ratio of $2.6: 1$. The age distribution is shown in table $1.52 \%$ of the patients were from El Obeid town or nearby locality, where as $48 \%$ of the patients came from distant rural areas. $37(74 \%)$ patients had lower limbs and $13(26 \%)$ patients had upper limb amputations. $33(66 \%)$ patients had elective operations. The commonest indication for amputation was sepsis $(40 \%)$, followed by trauma $(32 \%)$, vascular $(16 \%)$, mycetoma $(8 \%)$ and cancer $(4 \%)$. Comparison between the causes of amputation found in this study and the causes found in another study done in Khartoum was shown in table 2 .

Table 1: The age distribution.

\begin{tabular}{|c|c|c|}
\hline$A g e n$ yrs & $\mathrm{No}$ & 两 \\
\hline $00-15$ & 11 & 22 \\
\hline $16-30$ & 10 & 20 \\
\hline $31-45$ & 02 & 04 \\
\hline$>45$ & 27 & 54 \\
\hline Total & 50 & 100 \\
\hline
\end{tabular}

Table 2: Causes for amputations in El Obeid (OBD) and Khartoum (KRT).

\begin{tabular}{|c|c|c|}
\hline $\begin{array}{l}\text { Cause of } \\
\text { amputation }\end{array}$ & (\%) & $\begin{array}{r}0 \mathrm{KRT})^{* K} \\
\mathrm{n}^{2}=170\end{array}$ \\
\hline Sepsis & 40 & 30 \\
\hline Trauma & 32 & 42.4 \\
\hline Vascular & 16 & 04 \\
\hline Mycetoma & 08 & 17.6 \\
\hline Cancer & 04 & 3.5 \\
\hline $\begin{array}{l}\text { Congenital } \\
\text { malformations }\end{array}$ & 00 & 2.5 \\
\hline Total & 100 & 100 \\
\hline
\end{tabular}

${ }^{*} \mathrm{OBD}=$ Study in El Obeid Teaching Hospita. **KRT = Study in National Prothetic-Orthotic Centre in Khartoum, Sudan'.

\section{Discussion}

Amputation is as old as mankind. Today, it is performed as a form of treatment and not a purely life-saving procedure in response to injury or disease ${ }^{2,3}$. Later the target in amputee rehabilitation must be restoration of body image and to return an individual to an active productive 
role in the community. The data addressing this group of patients in developing countries are scarce $^{4,5}$. We could trace only two previous reports in a large country with diversities and many conflicts like Sudan ${ }^{5,6}$.

In this study $36(76 \%)$ patients were males. Males were more prone due to their exposure to trauma and possibly were more at risk for vascular atheromatous diseases by their smoking habits. $17(32 \%)$ patients underwent emergency procedures mainly for crushed lacerated wounds, fulminated sepsis or gas gangrene in diabetics.

Sepsis was the main cause of amputation and accounted for $20(40 \%)$ patients, followed by trauma which accounted for 16 patients $(32 \%)$. In Khartoum the main cause for amputations was trauma $(42.4 \%)$, followed by sepsis which accounted for $30 \%{ }^{5}$. It is interesting to notice that in both series, trauma and sepsis accounted for $72 \%$ of cases $^{7}$. Similar reports were published from other African and developing countries like Kenya, Nigeria, Niger, Malaysia, Saudi Arabia, and Ethiopia ${ }^{7-15}$. Such pattern was also reported in the developed countries like United Kingdom in the Nineteenth century ${ }^{16}$. Recent causes of amputations in the developed world were vascular particularly atherosclerosis, and tumor related ${ }^{17,18}$. Most of the amputations for sepsis in our study were performed in diabetic patients $(32 \%)$, compared to $24 \%$ diabetic amputations in Khartoum series. Diabetic angiopathy, neuropathy and susceptibility to infection were predisposing factors; but the situation was made worse by ignorance, inadequate control, lack of foot care and scarce facilities for free service in our health delivery system.

Trauma accounted for $32 \%$ of the amputations in this study. The main causes were Road Traffic Accidents in 3 patients, crush missile injuries in 4 patients, lacerated wounds of animal bites in 3 patients and gangrenous limbs due to post fracture manipulations and tight inappropriate splintage by traditional bone setters in 6 patients. Similar tragedy resulting from practices of native healers was reported from African communities ${ }^{8,19,20}$. Such miseries are definitely preventable through health education and the provision of a user-friendly health delivery system. Eshete described that offering a one-day instructional course to bone setters and two-day courses to local health assistants about the safe care of fracture, resulted in marked reduction in amputations ${ }^{20}$.

Thirteen patients $(26 \%)$ had major upper limb amputations. This is similar to the finding in
Nigeria $^{19}$. However, it is different from reports from Kenya ${ }^{7}$, Saudi Arabia ${ }^{14}$ and Thailand ${ }^{21}$.

Vascular causes constituted $16 \%$ of the study sample. Amputations were mainly performed in elderly patients with chronic limb ischaemia presenting with severe ischemic rest pain and/ or gangrene. Absence of special investigations in this hospital like Doppler Ultrasound and angiograms was responsible for the possible delay in diagnosis and implementation of definitive early vascular treatment in some cases. In the developed societies vascular disease is the major cause of lower limb amputations ${ }^{16,18}$.

Mycetoma foot is a special type of infection. It is a chronic, granulomatous, progressive and relatively painless inflarnmatory disease that involves the subcutaneous tissue after traumatic inoculation of the causative organism ${ }^{22}$. The victims were mainly farmers and herdsmen presenting late with ugly lesions and useless feet that necessitate amputation ${ }^{23}$. In this study mycetoma foot accounted for $8 \%$ of the amputations, where as it was $17.6 \%$ in the study reported from Khartoum ${ }^{5}$.

Among this study group, one diabetic patient presenting with Fournier's gangrene of the scrotum and gas gangrene of the foot died with septicaemia after a high above knee amputation. We could trace the death of other 3 patients at home for unknown exact reasons within 30 days of the amputation, accounting for an overall mortality rate of $8 \%$. Mortality rates ranging from $8.5 \%$ to $16 \%$ were reported ${ }^{7,11}, 16$.

Knowledge about the underlying causes of limb amputations would be helpful in planning public health strategies in each community. Sepsis including mycetoma, trauma and lower limb ischaemia, accounting for $96 \%$ of the causes in this study; are all potentially preventable diseases. The establishment of a special Diabetic Care Centre to high light foot care, aggressive management of diabetic foot lesions and to formulate local guide lines following St. Vincent's Declaration ${ }^{24}$ is needed.

The responsibility towards amputees must include provision of artificial limbs, together with the maintenance and replacement of the artificial limbs supplied ${ }^{25}$. The fact that our amputee patients have to travel hundreds of miles to the only Prosthetic-Orthotic Centre in Khartoum is neither practical nor acceptable. It is our moral duty that such a vital service for this special group 
of patients should be available in a reachable and easily affordable manner.

\section{Discussion}

Amputation is as old as mankind. Today, it is performed as a form of treatment and not a purely life-saving procedure in response to injury or disease ${ }^{2,3}$. Later the target in amputee rehabilitation must be restoration of body image and to return an individual to an active productive role in the community. The data addressing this group of patients in developing countries are scarce $^{4,5}$. We could trace only two previous reports in a large country with diversities and many conflicts like Sudan ${ }^{5,6}$.

In this study $36(76 \%)$ patients were males. Males were more prone due to their exposure to trauma and possibly were more at risk for vascular atheromatous diseases by their smoking habits. $17(32 \%)$ patients underwent emergency procedures mainly for crushed lacerated wounds, fulminated sepsis or gas gangrene in diabetics.

Sepsis was the main cause of amputation and accounted for $20(40 \%)$ patients, followed by trauma which accounted for 16 patients $(32 \%)$. In Khartoum the main cause for amputations was trauma $(42.4 \%)$, followed by sepsis which accounted for $30 \%{ }^{5}$. It is interesting to notice that in both series, trauma and sepsis accounted for $72 \%$ of cases $^{7}$. Similar reports were published from other African and developing countries like Kenya, Nigeria, Niger, Malaysia, Saudi Arabia, and Ethiopia ${ }^{7-15}$.Such pattern was also reported in the developed countries like United Kingdom in the Nineteenth century ${ }^{16}$. Recent causes of amputations in the developed world were vascular particularly atherosclerosis, and tumor related ${ }^{17,18}$. Most of the amputations for sepsis in our study were performed in diabetic patients $(32 \%)$, compared to $24 \%$ diabetic amputations in Khartoum series. Diabetic angiopathy, neuropathy and susceptibility to infection were predisposing factors; but the situation was made worse by ignorance, inadequate control, lack of foot care and scarce facilities for free service in our health delivery system.

Trauma accounted for $32 \%$ of the amputations in this study. The main causes were Road Traffic Accidents in 3 patients, crush missile injuries in 4 patients, lacerated wounds of animal bites in 3 patients and gangrenous limbs due to post fracture manipulations and tight inappropriate splintage by traditional bone setters in 6 patients. Similar tragedy resulting from practices of native healers was reported from African communities ${ }^{8,19,20}$. Such miseries are definitely preventable through health education and the provision of a user-friendly health delivery system. Eshete described that offering a one-day instructional course to bone setters and two-day courses to local health assistants about the safe care of fracture, resulted in marked reduction in amputations ${ }^{20}$.

Thirteen patients $(26 \%)$ had major upper limb amputations. This is similar to the finding in Nigeria ${ }^{19}$. However, it is different from reports from Kenya ${ }^{7}$, Saudi Arabia ${ }^{14}$ and Thailand ${ }^{21}$.

Vascular causes constituted $16 \%$ of the study sample. Amputations were mainly performed in elderly patients with chronic limb ischaemia presenting with severe ischemic rest pain and/ or gangrene. Absence of special investigations in this hospital like Doppler Ultrasound and angiograms was responsible for the possible delay in diagnosis and implementation of definitive early vascular treatment in some cases. In the developed societies vascular disease is the major cause of lower limb amputations ${ }^{16,18}$.

Mycetoma foot is a special type of infection. It is a chronic, granulomatous, progressive and relatively painless inflammatory disease that involves the subcutaneous tissue after traumatic inoculation of the causative organism ${ }^{22}$. The victims were mainly farmers and herdsmen presenting late with ugly lesions and useless feet that necessitate amputation ${ }^{23}$. In this study mycetoma foot accounted for $8 \%$ of the amputations, where as it was $17.6 \%$ in the study reported from Khartoum ${ }^{5}$.

Among this study group, one diabetic patient presenting with Fournier's gangrene of the scrotum and gas gangrene of the foot died with septicaemia after a high above knee amputation. We could trace the death of other 3 patients at home for unknown exact reasons within 30 days of the amputation, accounting for an overall mortality rate of $8 \%$. Mortality rates ranging from $8.5 \%$ to $16 \%$ were reported ${ }^{7}, 11,16$.

Knowledge about the underlying causes of limb amputations would be helpful in planning public health strategies in each community. Sepsis including mycetoma, trauma and lower limb ischaemia, accounting for $96 \%$ of the causes in this study; are all potentially preventable diseases. The establishment of a special Diabetic Care Centre to high light foot care, aggressive management of diabetic foot lesions and to formulate local guide lines following St. Vincent's Declaration ${ }^{24}$ is needed. 
The responsibility towards amputees must include provision of artificial limbs, together with the maintenance and replacement of the artificial limbs supplied ${ }^{25}$. The fact that our amputee patients have to travel hundreds of miles to the only Prosthetic-Orthotic Centre in Khartoum is neither practical nor acceptable. It is our moral duty that such a vital service for this special group of patients should be available in a reachable and easily affordable manner.

\section{References}

1. Robinson KP. Historical aspects of amputation. Ann Roy Coll Surg Engl. 1991; 73: 134-136.

2. Onubs O, Ediodiok E. The scope of amputation in developing world: a review of the literature. Postgrad Doctor. 1989; 11: 118-121.

3. Paudel B, Shrestha,BK, Banskota,AK. Two faces of major lower limb amputations. Kathmandu Medical Journal. 2005; 3(3): 212-216.

4. Gregory-Dean A. Amputations: statistics and trends. Ann Roy Coll Surg Engl. 1991; 73: 137-142.

5. Mohmed IA, Ahmed ARM, Ahmed ME. Amputation and prostheses in Khartoum. JR Coll Surg Edinb. 1997; 42: 1-4.

6. Shaheen $\mathrm{S}$. Experience with amputations and prosthetic rehabilitation in Khartoum. Sud Med J. 2004; 41(2\&3): 16-19.

7. Muyembe VM, Muhinga MN. Major limb amputation at a provincial general hospital in Kenya. East Afr Med I. 1999; 76(3): 163-166.

8. Yakubu A, Muhammad I, Mabogunje OA. Major limb amputation in adults, Zaria, Nigeria. $J R$ Coll Surg Edinb. 1996; 41(2): 102-104.

9. Ogunlade $\mathrm{SO}$, Alonge $\mathrm{TO}$, Omolou $\mathrm{AB}$, et al. Major limb amputation in Ibadan. Afr $J$ Med Med Sci. 2002; 31(4): 333-336.

10. Akiode O, Shonubi AM, Musa A, et al. Major limb amputations: an audit of indications in a suburban surgical practice. J Natl Med Assoc. 2005; 97(1): 76-78.

11. Kidmas AT, Nwadiaro $\mathrm{CH}$, Igun GO. Lower limb amputation in Jos, Nigeria. East Afr Med J 2004; 81(8): 427-429.
12. Olaolorun DA. Amputations in general practice. Niger Postgrad Med J. 2001; 8(3): 133-135.

13. Hazmy W, Mahamud M, Ashikin N, et al. Major limb amputations in Seremban Hospital: a review of 204 cases from 1997-1999. Med J Malaysia. 2001; 56 Suppl C: $3-7$.

14. Al-Turaiki HS, Al-Falahi LA. Amputee population in the Kingdom of Saudi Arabia. Prosthet Orthot Int. $1993 ; 17(3): 147-156$.

15. Lester FT. Amputations in patients attending a diabetic clinic in Addis Abeba, Ethiopia. Ethiop Med J. 1995; 33(1): $15-20$.

16. Galland RB. Nineteenth century amputations at the Royal Berkshire Hospital, Reading. Ann R Coll Surg Engl. 2003; 85(6): 393-6.

17. Kim YC, Park CI, Kim DY, Kim TS, Shin JC. Statistical analysis of amputation and trends in Korea. Prosthet Orthot Int. 1996; 20(2): 88-95.

18. Carmona GA, Hoffmeyer P, Herrmann FR et al. Major lower limb amputations in the elderly observed over ten years: the role of diabetes and peripheral arterial disease. Diabetes Metab. 2005; 31(5): 449-454.

19. Ekere AU. The scope of extremity amputations in a private hospital in the south-south region of Nigeria. Niger J Med. 2003; 12(4): 225-228.

20. Eshete $M$. The prevention of traditional bone setter's gangrene. J Bone and Joint S. 2005; 87 B (1): 102-03.

21. Settakorn J, Rangdaeng $\mathrm{S}$, Arpornchayanon $\mathrm{O}$ et al. Why were limbs amputated? An evaluation of 216 surgical specimens from Chiang Mai University Hospital, Thailand. Arch Orthop Trauma Surg. 2005; 125(10): 701-705.

22. Fahal AH, Suliman SH. Clinical presentation of mycetoma. Sudan Med. J. 1994; 32 (2): 46-66.

23. Fahal AH, Hassan MA. Mycetoma. Br J Surg. 1992; 79(11): 1138-1141.

24. Bergrem H, Kalo I, Babic D, et al. Diabetes care in Europe: The St. Vincent's Declaration coming of age? Diabet. Nutr. Metab. 1996; 9(6): 330-336.

25. Staats TB. The rehabilitation of amputee in developing world: a review of the literature. Prosthet Orthot Int. 1996; $20: 45-50$ 